\title{
INTERFACIAL DYNAMIC VELOCITY FOR SOLAR CELL CHARACTERIZATION
}

\author{
J. FARAH ${ }^{\mathrm{a}}$, B. AZAR ${ }^{\mathrm{a}}$, A. KHOURY ${ }^{\mathrm{a}}$ and P. MIALHE ${ }^{\mathrm{b}, *}$ \\ 'Laboratoire de Physique des Semiconducteurs et Enérgetique, Faculté des

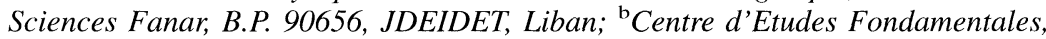 \\ Université de Perpignan, 66860 PERPIGNAN Cedex, France
}

(Received 29 July 1996; In final form 30 August 1996)

\begin{abstract}
A new parameter for solar cell characterization has been introduced. The $n-p$ junction has been considered as an active interface and an interfacial dynamic velocity is defined at the base boundary of the space charge region. We show that this interfacial dynamic velocity depends on the base width, base doping profile, and the recombination velocity at the device back surface. Additionally, it is shown to be a function of the operating conditions such as the applied potential and the illumination level.
\end{abstract}

\section{INTRODUCTION}

Photovoltaic energy conversion is a coming source of electrical power. The basic mechanisms in solar cells are now understood and modelling techniques have led to the optimization of the device structures. Largescale manufacturing of new fabrication technologies have been developed and there is rising interest in the use of concentrating systems to increase the solar cell output power per $\mathrm{cm}^{2}$, in order to reduce the cost of photovoltaic systems. A limitation of the expected effect appears resulting from high injection effects, which modify the fundamental physical processes of carrier transport in the cell.

Recent studies [1-3] have shown a degradation of the efficiency of solar cells at high illumination levels because of carrier recombination in the

*Corresponding author. 
space charge region (SCR) at the junction. The SCR behaves like an active interface. Until now, no parameters have been introduced to define the properties of solar cell junction under illumination.

Modelling techniques leading to the characterisation of MetalSemiconductor interfaces have introduced a recombination velocity $[4,5]$ that was used later on to describe the back interface of back surface field [BSF] solar cells [6,7]. This was done with the microscopic modelling of the $p-p+$ interface.

In this paper, we introduce an interfacial dynamic velocity in order to characterize the junction as an active interface. It considers the excess minority carrier profile in the solar cell base under illumination. The interfacial dynamic velocity is shown to be a function of the illumination level, the operating conditions, and the physical structure of the cell.

\section{THEORY}

A common practice to describe the rate at which carriers are lost at semiconductor interface [4] is the introduction of a surface recombination velocity $\mathrm{S}$. The interface current density $\mathrm{J}$ is written $[5,8]$ :

$$
\mathrm{J}=-\mathrm{qnS}
$$

where $n$ is the excess minority carrier density close to the interface and $q$ the electron charge. In order to introduce an interfacial dynamic velocity for characterisation of the $n-p$ interface of a solar cell we consider an $n+$ -p junction (Fig. 1).

Let $\mathrm{n}(\mathrm{x})$ be,the minority carrier excess density of the $p$ type base region with the origin of the $x$ axis taken at the physical junction. Assuming that the SCR in the $p$ region, $(0 \leq \mathrm{x} \leq \mathrm{Wp})$ is depleted, we define an Interfacial Dynamic Velocity (IDV) $S_{d}$ depending on the minority carrier density at the interface $x=W p$. In $1 \mathrm{D}$ modelling, the flux of the total current density $\mathrm{J}$ across the interface is given by:

$$
\frac{\mathrm{J}}{\mathrm{q}}=\left.\mathrm{D}_{\mathrm{n}} \frac{\mathrm{dn}(\mathrm{x})}{\mathrm{dx}}\right|_{\mathrm{x}=\mathrm{Wp}_{\mathrm{p}}}+\left.\mu_{\mathrm{n}} \mathrm{n}(\mathrm{x}) \mathrm{E}(\mathrm{x})\right|_{\mathrm{x}=\mathrm{Wp}_{\mathrm{p}}}
$$




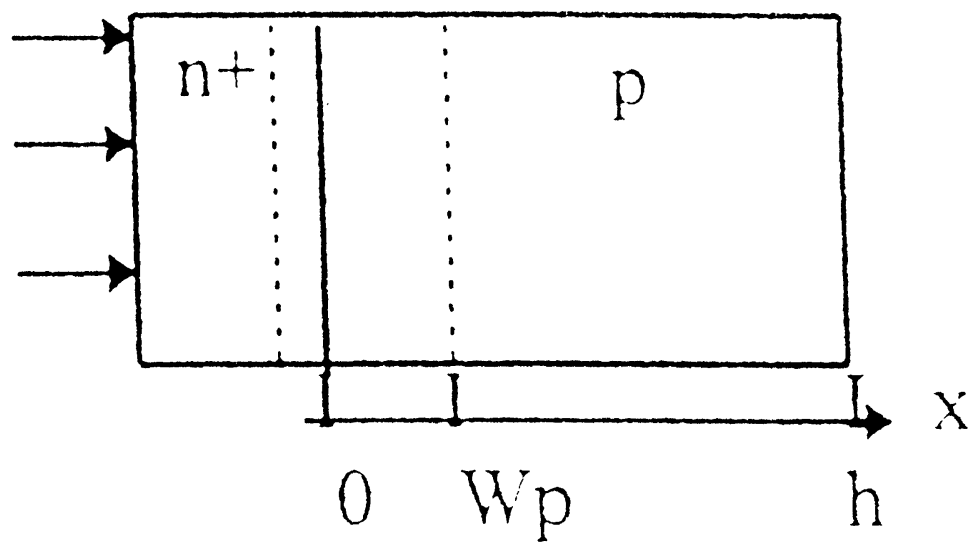

FIGURE 1 Schematic structure of $n^{+}-p$ solar cell for present calculations.

where $D_{n}$ and $\mu_{n}$ are, respectively, the electronic diffusion coefficient and mobility. $E(x)$ is the electric field. Equations (1) and (2) lead us to define the IDV at the $\mathrm{x}=\mathrm{Wp}$ interface through:

$$
-\left.D_{n} \frac{d n(x)}{d x}\right|_{x=W_{p}}-\left.\mu_{n} n(x) E(x)\right|_{x=W_{p}}=n(W p) S_{d}
$$

Equation (3) is a boundary condition and $S_{d}$ is a function of the physical parameters of the solar cell through the carrier density $n(x)$. Further, $S_{d}$ is dependent on the actual operating conditions (potential at the junction $V j$ and illumination level).

\subsection{Determination of $n(x)$ :}

The minority excess carrier density is obtained from the solution of the continuity equation in the steady state taking into account the lightinduced, space-dependent, carrier-generation rate $\mathrm{g}(\mathrm{x})$ :

$$
D_{n} \frac{d^{2} n(x)}{d x^{2}}+\mu_{n} n(x) \frac{d E(x)}{d x}+\mu_{n} E(x) \frac{d n(x)}{d x}-\frac{n(x)}{\tau_{n}}+g(x)=0
$$

where $\tau_{n}$ is the minority carrier lifetime in the base. A good approximation of the function $\mathrm{g}(\mathrm{x})$ is given by [9]: 


$$
g(x)=\sum_{i 1}^{5} a_{i} \exp \left(-b_{i} x\right)
$$

The coefficients $a_{i}$ and $b_{i}$ are taken in the AM1 illumination conditions. Equation (4) is solved under the boundary conditions at the junction:

$$
n(W p)=\frac{n_{i}^{2}}{N_{A}}[\exp (q V j / k T)-1]
$$

and at the back surface:

$$
-\left.D_{n} \frac{d n(x)}{d x}\right|_{x=h}=\left.S_{b} n(x)\right|_{x=h}
$$

where $n_{i}$ is the intrinsic density, $N_{A}$ the acceptor doping density in the base, and $\mathrm{S}_{\mathrm{b}}$ the back recombination velocity of the solar cell at $\mathrm{x}=\mathrm{h}$.

The electric field is taken as $\mathrm{E}=\mathrm{Vj} / \mathrm{h}$ in order to develop this model and solve Eq. (4). In this case, the carrier density is given by:

$$
n(x)=A \exp \left(r_{1} x\right)+B \exp \left(r_{2} x\right)+\sum_{i=1}^{5} \alpha_{i} \exp \left(-b_{i} x\right)
$$

where

$$
\begin{aligned}
& r_{1}=\frac{-\mu_{n} E+\sqrt{\left(\mu_{n} E\right)^{2}+4 \frac{D_{n}}{\tau_{n}}}}{2 D_{n}} \\
& r_{2}=\frac{-\mu_{n} E-\sqrt{\left(\mu_{n} E\right)^{2}+4 \frac{D_{n}}{\tau_{n}}}}{2 D_{n}}
\end{aligned}
$$

and

$$
\alpha_{i}=-\frac{a_{i}}{D_{n} b^{2}{ }_{i}-\mu_{n} E b_{i}-\frac{1}{\tau_{n}}}
$$


The constants A and B are determined from the boundary conditions (6) and (7). They are given by:

$$
\begin{aligned}
& \mathrm{A}= \\
& \frac{\sum_{i=1}^{5}\left(D_{n} b_{i}-S_{b}\right) \alpha_{i} \exp \left(r_{2} W p-b_{i} h\right)-\left(S_{b}+r_{2} D_{n}\right)\left[n(W p)-\sum_{i=1}^{5} \alpha_{i} \exp \left(-b_{i} W p\right)\right] \exp \left(r_{2} h\right)}{\left(S_{b}+r_{1} D_{n}\right) \exp \left(r_{1} h+r_{2} W p\right)-\left(S_{b}+r_{2} D_{n}\right) \exp \left(r_{1} W p+r_{2} h\right)} \\
& \mathrm{B}= \\
& \frac{\left[-2\left(S_{b}+r_{2} D_{n}\right) \exp \left(r_{2} h\left(r_{1}-r_{2}\right) W p\right)-\left(S_{b}+r_{1} D_{n}\right) \exp \left(r_{1} h\right)\right]\left[n(W p)-\sum_{1=1}^{5}\left(D_{n} b_{1}-S_{b}\right) \alpha_{1} \exp \left(r_{1} W_{p}-b_{1} h\right)\right]}{\left(S_{b}+r_{1} D_{n}\right) \exp \left(r_{1} h+r_{2} W p\right)-\left(S_{b}+r_{2} D_{n}\right) \exp \left(r_{1} W p+r_{2} h\right)}
\end{aligned}
$$

The excess carrier density profiles versus $x$ for a set of illumination levels are shown in Fig. 2. We notice a large increase in the maximum of the excess carrier density profile near the interface.

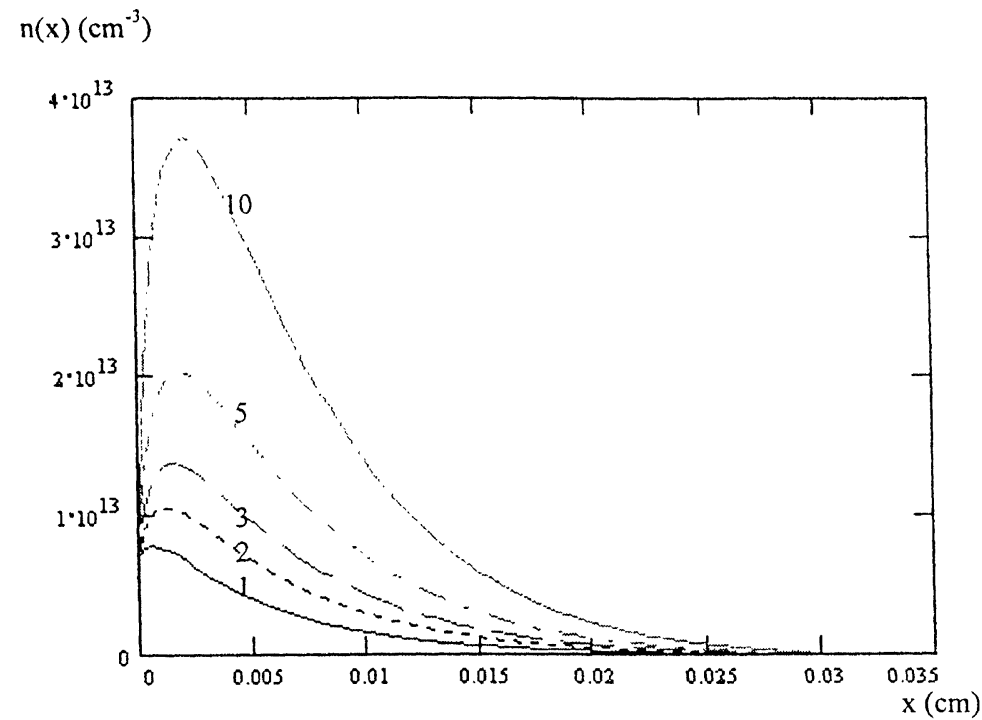

FIGURE 2 The distribution of the minority density $n(x)$ in the base for increasing illumination levels and for the operating potential $\mathrm{Vj}=0.5$ Volt. The parameters of the solar cell are: $\mathrm{N}_{\mathrm{A}}=10^{16} \mathrm{~cm}^{-3} ; \mathrm{S}_{\mathrm{b}}=10^{5} \mathrm{~cm} \cdot \mathrm{s}^{-1}$ and $\mathrm{h}=0.03 \mathrm{~cm}$. The light concentration factor is indicated on the graph (rising from 1 sun to 10 suns). 
This figure shows a gradient of $\mathrm{n}(\mathrm{x})$ in the junction region larger than in the base. It increases the diffusion current and is responsible for the modification of the cell performances.

\subsection{Determination of Sd.}

Equations (7)-(12) lead to express $S_{d}$ as:

$$
S_{d}=-\frac{D_{n}\left[A r_{1} \exp \left(r_{1} W p\right)+B r_{2} \exp \left(r_{2} W p\right)-\sum_{i=1}^{5} \alpha_{i} b_{i} \exp \left(-b_{i} W p\right)\right]}{A \exp \left(r_{1} W p\right)+B \exp \left(r_{2} W p\right)+\sum_{i=1}^{5} \alpha_{i} \exp \left(-b_{i} W p\right)}
$$

The behavior of the interfacial dynamic velocity $S_{d}$ as a function of $\mathrm{Vj}$ and its dependence on the illumination level is displayed in Fig. (3). This figure shows that $S_{d}$ decreases with $\mathrm{Vj}$, and the greater the illumination

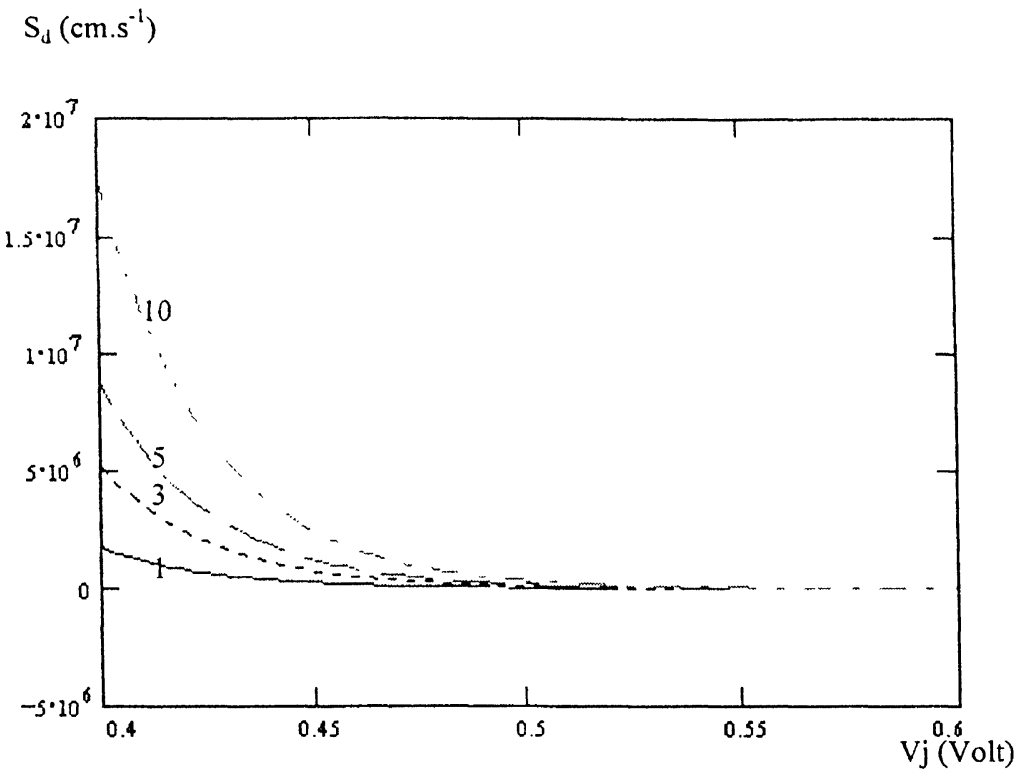

FIGURE 3 Variations of $S_{d}$ versus $V j$ for increasing illumination levels. The parameters of the base of the solar cell are: $\mathrm{N}_{\mathrm{A}}=10^{16} \mathrm{~cm}^{-3} ; \mathrm{S}_{\mathrm{b}}=10^{5} \mathrm{~cm} \cdot \mathrm{s}^{-1}$ and $\mathrm{h}=0.03 \mathrm{~cm}$. The light concentration factor is indicated on the graph (rising from 1 sun to 10 suns). 
(number of suns), the larger the drop in its magnitude. For large values of $\mathrm{Vj}$ (close to the open circuit value), $\mathrm{S}_{\mathrm{d}}$ approaches the limiting value of $2.10^{4} \mathrm{~cm} . \mathrm{s}^{-1}$, whatever the illumination level. In contrast, for values of $\mathrm{Vj}$ corresponding to actual operating conditions, we notice a great dependency of $S_{d}$ upon illumination. For instance, when $\mathrm{Vj}=0.4 \mathrm{~V}, \mathrm{~S}_{\mathrm{d}}$ increases from $1.710^{6} \mathrm{~cm} . \mathrm{s}^{-1}$ to $1.710^{7} \mathrm{~cm} . \mathrm{s}^{-1}$ when illumination rises from 1 sun to 10 suns. The IDV value reflects the effectiveness of the junction interface at the active border of the space charge region.

For a one sun illumination and $\mathrm{Vj}=0.4 \mathrm{~V}$, we have obtained a value for $\mathrm{S}_{\mathrm{d}}=1.710^{6} \mathrm{~cm} \cdot \mathrm{s}^{-1}$ whereas for $\mathrm{Vj}=0.5 \mathrm{~V}, \mathrm{~S}_{\mathrm{d}}=2.410^{4} \mathrm{~cm} \cdot \mathrm{s}^{-1}$. The great sensitivity of the IDV to the operating conditions is related to minority carrier concentration at the junction interface. Low values of the IDV are indicative of weak current flow.

The effect of the physical parameters such as the base doping $\mathrm{N}_{\mathrm{A}}$ and the back surface recombination velocity $S_{b}$ are shown in figures (4) and

$$
\mathrm{S}_{\mathrm{d}}\left(\mathrm{cm} \cdot \mathrm{s}^{-1}\right)
$$

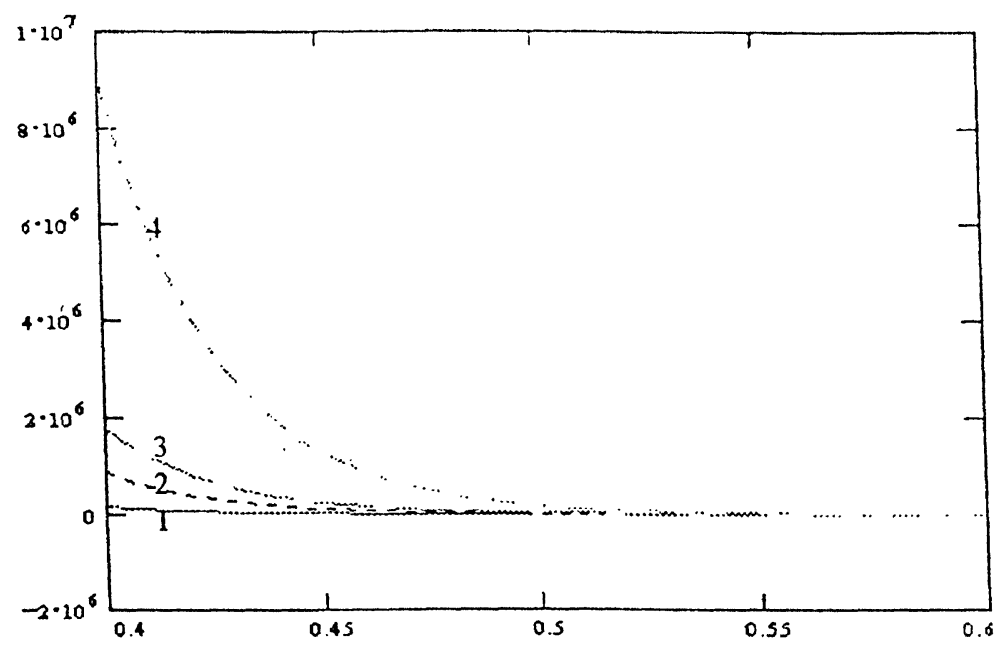

Vj (Volt)

FIGURE 4 The variations of $S_{d}$ versus $\mathrm{Vj}$ for different concentrations $\mathrm{N}_{\mathrm{A}}$ in the base under one sun illumination. $1 \mathrm{~N}_{\mathrm{A}}=10^{15} \mathrm{~cm}^{-3} ; 2 . \mathrm{N}_{\mathrm{A}}=5.10^{15} \mathrm{~cm}^{-3} ; 3 . \mathrm{N}_{\mathrm{A}}=10^{16} \mathrm{~cm}^{-3} ; 4 . \mathrm{N}_{\mathrm{A}}$ $=5.10^{16} \mathrm{~cm}^{-3}$. The parameters of the base of the solar cell are: $\mathrm{h}=0.005 \mathrm{~cm}$ and $\mathrm{S}_{\mathrm{b}}=10^{5}$ $\mathrm{cm} \cdot \mathrm{s}^{-1}$. 
(5).

We note that the variations of $S_{d}$ show a large sensitivity with respect to $\mathrm{N}_{\mathrm{A}}$ and $\mathrm{S}_{\mathrm{b}}$ when $\mathrm{Vj}$ is in the $0.4 \mathrm{~V}-0.5 \mathrm{~V}$ range. This results from the increase of the photocurrent with the base doping level and large values are indicative of high junction space charge. However, the effects of $S_{b}$ on $S_{d}$ are greater in solar cells with relativity narrow bases of the order of 50 $\mu \mathrm{m}$ (Fig. 5). For standard solar cells (base width of the order of 200 $\mu \mathrm{m}-300 \mu \mathrm{m})$, the effect of $S_{b}$ on $S_{d}$ is not significant. This result was expected since the minority carriers recombined before reaching the back contact.

\section{CONCLUSION}

This work introduces a new parameter for solar cell characterization, the interfacial dynamic velocity $S_{d}$, which is related to the cell illumination

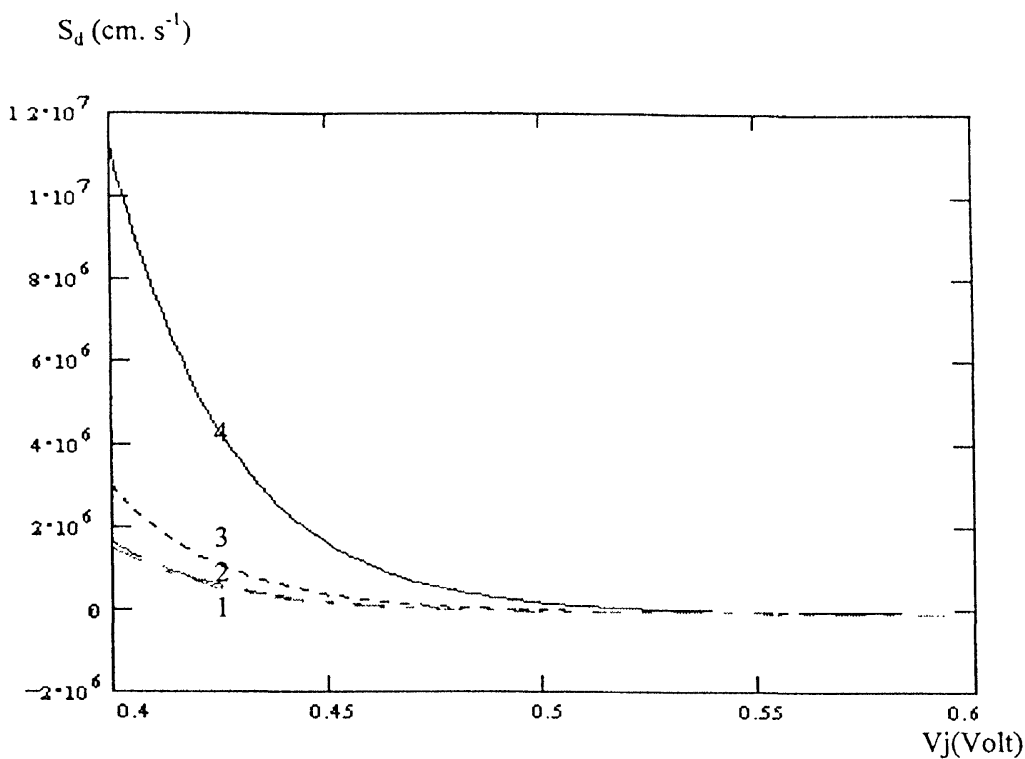

FIGURE 5 The variations of $S_{d}$ versus $\mathrm{Vj}$ for different back surface recombination velocities under one sun illumination. $1 . \mathrm{S}_{\mathrm{b}}=10^{2} \mathrm{~cm} \cdot \mathrm{s}^{-1} ; 2 . \mathrm{S}_{\mathrm{b}}=10^{3} \mathrm{~cm} \cdot \mathrm{s}^{-1} ; 3 . \mathrm{S}_{\mathrm{b}}=10^{4} \mathrm{~cm} . \mathrm{s}^{-1}$; 4. $\mathrm{S}_{\mathrm{b}}=10^{5} \mathrm{~cm} \cdot \mathrm{s}^{-1}$. The parameters of the base of the solar cell are: $\mathrm{h}=0.005 \mathrm{~cm}$ and $\mathrm{N}_{\mathrm{A}}$ $=10^{16} \mathrm{~cm}^{-3}$ 
level. Its dependence on the cell technological parameters in normal operating conditions, has been discussed.

The interfacial dynamic velocity has been shown to be a practical parameter to describe the effectiveness of the solar cell under illumination. It should be of interest for modelling studies to optimize solar cell structure for light concentration operative conditions.

\section{References}

[1] Walters, R. J., Messenger, S. R., Summers, G. P., Burke, E. A. and Keavney, C. J. (1991). IEEE Trans. on Nuc. Sc., 38, 1153-58.

[2] Mialhe, P., de la Bardonnie, M., Le Bras, L., El Hajj, K. and Khoury, A. World Renewable Energy Congress III, 11-16 Sept. 1994. READING (U.K.), III, 1651-53.

[3] Mialhe, P., Affour, B., El Hajj, K. and Khoury, A. (1995). Active and Passive Electronic Components, 17, 227-32.

[4] Sze, S. M. Phys. of Semiconductor Devices, 2nd Ed. (Wiley-Interscience, 1981).

[5] Sah, C. T. (1986). Solar Cells, 17, 1-27.

[6] Rose, B. H. and Weaver, H. T. (1983). J. Appl. Phys., 54, 238-47.

[7] Sing, S. N. and Sing, P. K. (1990). Solid-St Electronics, 33, 968-70.

[8] Tewary, V. K. and Jain, J. C. (1986). Advances in Electronic and Electron Physics, 67, 329-414.

[9] Furlan, J. and Amon, S. (1985). Solid-St Electronics, 28, 12, 1241-1243. 

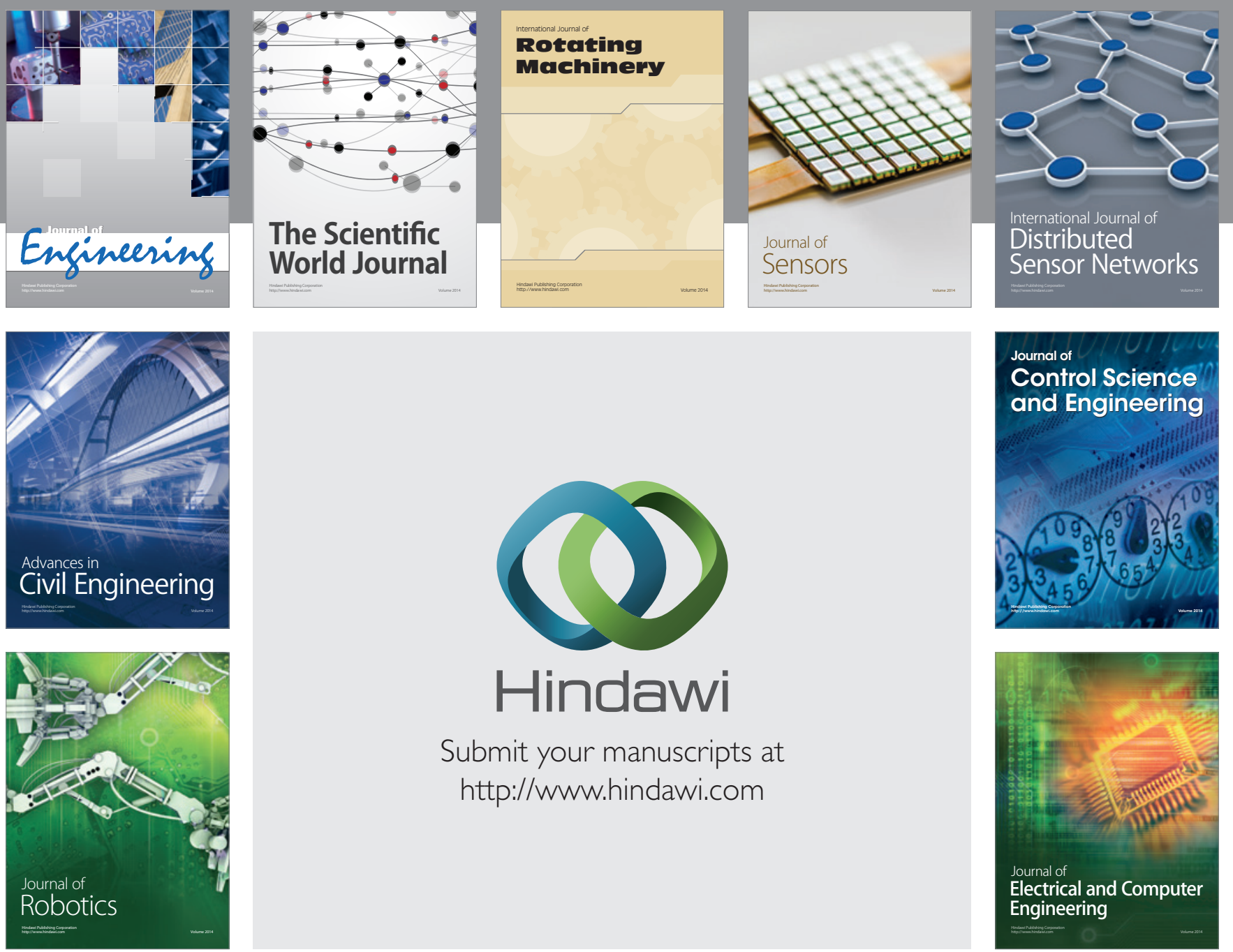

Submit your manuscripts at

http://www.hindawi.com
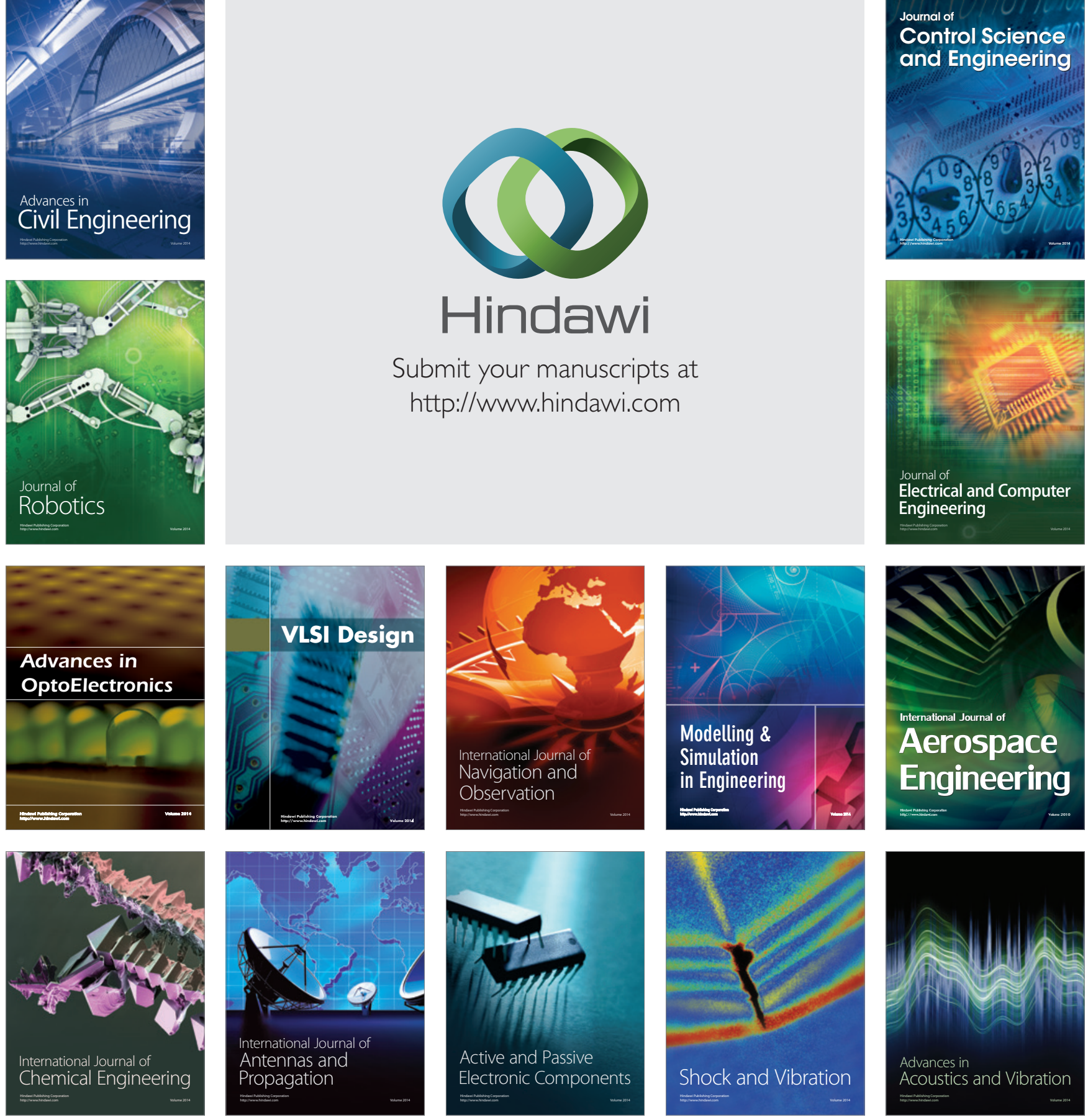